\title{
A Brief Literature Review of Juvenile Statistics, A Comparative Analysis of Current Racial Differences Within the Criminal Justice System
}

\author{
Phillip D. Clingan
}

\author{
Pierce College, Criminal Justice Department, USA \\ *Corresponding author details: Dr. Phillip D. Clingan; dr.phillipclingan@gmail.com
}

\begin{abstract}
Youths under 18 years get trapped into the Juvenile Justice System after being suspected of committing a delinquent or criminal act. The United States tops in Juvenile arrests in the world. States like West Virginia, Alaska, Oregon, South Dakota, and Wyoming have the highest number of juveniles. However, an estimated 2.1 million youths under 18 years were arrested in the United States during a single year. This paper aims to address the current racial differences that exist within the criminal justice system. By addressing challenges like youths of color are more likely to be committed than white youths into the juvenile system will assist in curbing racial disparity. Statistics reveal that $42 \%$ of youths in the placement holdings are black youths, even though black youths make up for $16 \%$ of youths all over the United States. In California alone, African American juveniles take $27.5 \%$ while whites take up $15 \%$.

Even though the system's laws contain no racial bias, research shows that discrimination can occur where the system allows criminal justice officials discretion in handling offenders. Black youths take up for $15 \%$ of the total number of youths in the USA get they have the highest juvenile detentions of $42 \%$, but it is difficult to deny these records since there is evidence like arrest and imprisonment records to back up this claim. The racial disparities exist from targeting the blacks, arrest, sentencing, imprisonment, and release. These actions promote discrimination among the black youths, and black youths are likely to get significant sentencing compared to whites for the same crimes committed. Different states in the United States have different racial disparities, California and Texas, blacks serve long sentences, unlike the whites.

There are various causes of racial disparities like; some black residences are known for crime, and they have huge offence rates, unequal access to resources, judicial decisions, and racial prejudice. After the research, it was evident that racial disparity exists, and it can only be corrected by looking at the root cause of the problem widely, which is discrimination. Race plays a significant role when it comes to juvenile detentions. Youths of color are four times more probable to be detained, unlike white youths. The research designed a method of tracking racial disparities via a hypothetical juvenile jurisdiction criminal justice system. The paper will extensively dive into juvenile population characteristics, juvenile justice system structure, law enforcement, juvenile crime, juveniles in court, juveniles on probation by the state, juveniles in the correction by the state and foreign nations, and an analysis of all the findings. The extensive research will be able to answer all the questions to the problem of racial disparity.
\end{abstract}

Keywords: juvenile statistics; comparative analysis; racial differences; criminal justice system; juvenile crime; law enforcement

\section{INTRODUCTION}

The United States of America is the most diverse racial demographic nation in the entire world. However, not all proceeds are equally shared since the same sections of the ethnic groups in the USA have become marginalized. The significant aspect of marginalization being how people of color are treated. Racial discrimination occurs in all aspects of the American government. It is a more significant problem when racial disparities occur even in the justice system, affecting persons of color. Discrimination prevents social justice from prevailing. The majority of people in the justice system, more so the juvenile justice system, are aware of the racial disparities in the system, but most look the other way since it is a norm ("Racial and Ethnic Disparities," 2021).

The paper's primary purpose is to discover the significant causes of racial disparity and discuss what actions can be taken within the juvenile justice system to curb racial disparity.
We promptly recognize that racial dissimilarity is characteristic of issues in society as an entirety, but in any case, keep up those actions can be taken to diminish difference. This paper is the product of a thorough procedure of gathering negotiations and talks with specialists within the field and an orderly survey of best practices and guidelines countrywide. The main objectives of the paper were;

I. Discover whether the evidence suggests that the juvenile justice system steadily treats minorities (blacks) differently from whites.

II. If the evidence suggests that racial disparity exist, is it because of discrimination, or the system is just reacting to the crime rates committed by the blacks, and

III. Deliberate on the policy implications for amending any bias. 
There are several causes of racial disparities, and they are manifested differently in the juvenile criminal justice structure. The paper's primary focus is on the specific manner in which these disparities may begin from decision-making in sections of the criminal justice system and the steps that the juvenile criminal justice system can prevent those effects. It is outlined for utilization as a reference manual for specialists and offers methodologies for surveying racial indifference. It moreover provides practices, policies, and procedures to diminish disparity at each category in the system. Tendering to racial dissimilarity inside the criminal justice system is reliable with a pledge to public safety and a reasonable equity framework. If baseless racial aberrations can be decreased, the justice system will pick up validity and serve a more prosperous part in curbing and preventing crime ("Racial and Ethnic Disparities," 2021).

Racial inequality within the criminal justice system occurs when the extent of a racial or ethnic group inside the control of the framework is more prominent than the proportion of such groups within the standard population. The causes of such difference are changed and can incorporate varying levels of criminal activity, law enforcement accentuation on specific groups, jurisdictive guidelines, and verdict making by criminal justice practitioners who work out wide watchfulness within the equity handle at one or more stages within the framework. There are several ways in which racial disparity can be addressed within the juvenile justice system. One by acknowledging the growing manner of racial disparities, two inspiring communications across all stakeholders and decision-makers within the justice system, vouching for systemic change, and lastly, acknowledging that one decision made does not impact all aspects within the system ("Racial and Ethnic Disparities," 2021).

\section{JUVENILE POPULATION CHARACTERISTICS BY STATE}

A study carried out in 2019 revealed that in a population of 73 million juvenile Americans, one in every five was under 18 years. Almost $50 \%$ of the total population were females under 18 years, and $54 \%$ of the total were under the age of 10 years. The non-Hispanic white took up 52\% of the population after the 2019 youth population, nonHispanic black youth accounted for $15 \%$, and Hispanic youth accounted for $26 \%$. Race and ethnicity outlines differ across all stats; white, non-Hispanic youth accounted for the significant share of the youth population in 45 states in 2019. Nine out of every ten juveniles in Maine, Vermont, and West Virginia were non-Hispanic and white. Whereas in New Mexico juvenile population was $60 \%$ Hispanic. Other states reported high Hispanic juvenile populations like California 51\%, Texas 48\%, Arizona 45\%, and Nevada $40 \%$ (Justice, 2021)

In 2019 majority of all Hispanic juveniles resided in California, Florida, and Texas. The states that recorded the highest number of non-Hispanic black juveniles in their populations in 2019 were Mississippi (42\%), Louisiana (37\%), Georgia (36\%), Maryland (32\%), South Carolina (30\%), and Alabama (31\%). At the same time, black youths accounted for $55 \%$ of the juvenile population in the District of Columbia. In 2019, 5 states reported juvenile populations with at least $10 \%$ American Indians or Alaska Natives. These states were Alaska (21\%), South Dakota (13\%), Oklahoma (12\%), New Mexico (10\%), and Montana (12\%). However, research projects that there will be an increase in the youth population under 18 years to rise by $2 \%$ in 2020 and 2030 and probably by $4 \%$ by 2035 . Because of the changes, race and ethnicity profiles in the United States youth will change by 2030 . The race and cultural minorities will account for the more significant portion of the youth population under 18 , which will rise even more by 2045 (Justice, 2021).

\section{JUVENILE JUSTICE SYSTEM STRUCTURE}

The juvenile justice system method involves nine critical choices ranges: arrest, referral to court, diversion, secure detainment, a legal waiver to grown-up criminal court, case requesting, wrongdoing finding/ settling, probation, and in conclusion, a private situation that includes imprisonment in a secure remedial office. Most cases are commonly sent to the adolescent equity framework through association with the police. The remaining cases are regularly dealt with by the probation officers, school authorities, or guardians at times. Most court offenses are property offenses, individual offenses, drugs, and common wrongdoing charges. Other referrals are from families, schools, probation officers, or social laborers. Probation officers and lawyers are the ones that decide whether the case requires the consideration of the adolescent court or the case can be taken care of in other ways like drug treatment rehabilitation (Sims et al., 2021).

When the case continues to the court, the authorities have to decide if the youth can be discharged to the parent/ guardian or whether the youth require to be put in a secure detainment center. In deciding this, the court tries to discover the youth's risk or threat to society or if the youth might elude. On the off chance that the case is settled in court, the province attorneys are required to file a petition. When the youth have a formal hearing, it is alluded to as an arbitration rather than a trial for grown-ups. The settling of the youth as a reprobate can lead to two results; rejection of the charges or control in a secure office. In most adolescent cases, the minimum restraining choice is often picked to put the youth on probation (Vasan, 2020)

\section{LAW ENFORCEMENT, JUVENILE CRIME, AND JUVENILES IN COURT}

After an arrest of a juvenile, it is up to the police officer to determine whether the juvenile will move deeper into the justice system or will be diverted. Police officers, social workers, probation officers, and other law enforcement personnel trail the magnitude and features of crimes reported. They utilized the information provided to keep a close watch on the shifting levels of crime in communities. Not all law violation crimes are reported to the police, and not all reported cases are solved. Law enforcement's new improper-based announcing frameworks incorporate casualty reports of offender characteristics in violations in which the victim sees the offender; for these wrongdoings, despite no arrest is made, law enforcement records can be utilized to create a layout of juvenile felonies (de Sequeira, 2021). For other types of wrongdoings, an understanding of juvenile contribution comes from the analysis of arrest statistics. Arrest statistics can survey the flow of juveniles and adults that go into the justice system. This is the primary source of any information on juvenile crime statistics and records.

\section{JUVENILES ON PROBATION AND IN CORRECTION CENTERS IN THE UNITED STATES AND OTHER NATIONS}

About $57 \%$ of adjudicated youth are placed on probation. In a system that is biased when it comes to probation, racial disparity exists in communal administration with several early release and experimentation structures giving regulation with slight sustenance, and the available indication suggests that early release and probation officials are to be expected to withdraw people of color than whites due to equivalent behaviors. Like the Urban Institute's examination of probation revocation rates in Dallas Province, Texas; Iowa's Sixth Judicial District; Multnomah Province, Oregon; and New York City uncovered that black probationer was canceled at unequal charges, this raised worries around the occurrence of biases to the disadvantaged people of color parolees. 
When it comes to juveniles of color, very few are put on probation ("Florida Juvenile Justice Probation and Community Intervention | Florida Department of Juvenile Justice", 2021).

In the United States, more than 47000 juvenile youth are put into correctional facilities due to the juvenile justice system. Majority are detained in prohibitive, reformationstyle offices, and many hundreds of others are detained without having had a trial. But indeed, the vast numbers speak to huge advancement: Since 2000 , the number of youths in correctional facilities has gone down by $60 \%$, a drift that appears no sign of abating down. Black Americans and Indians are the majority in juvenile facilities. Racial disparities can be witnessed even when transferring youths from juvenile to adult court. In 2017, about $35 \%$ of delinquency cases among black youths, but over 53\% of youths were transferred to adult court. Whereas whites comprised almost $45 \%$ of delinquency cases, only $30 \%$ of these cases were transferred to adult court ("Florida Juvenile Justice Probation and Community Intervention | Florida Department of Juvenile Justice", 2021).

The majority of youths are in correctional facilities. More than $91 \%$ of youths in juvenile facilities are in locked facilities. In locked facilities, handcuffs, leg cuffs, and restraining chairs can be used for the juveniles. More than $80 \%$ of juveniles are held in extensive facilities with more than 20 residents and long-term facilities where juveniles can be held for a month, six months, or even over a year (Quin et al., 2021). The most significant share of limited youth is held in detainment centers. These are the valuable reciprocals of correctional facilities within the grown-up criminal equity framework. Like correctional facilities, neighborhood specialists ordinarily work and are utilized for the transitory prohibitive guardianship of litigants anticipating a mentioning or minimum (verdict). More than $61 \%$ of youth in detainment facilities fall under these two groups.

\section{CONCLUSION}

Social disparities give room to societal bias and unfair treatment of juveniles. I believe each individual should answer for their actions without looking at them as a race. This paper has determined that social disparities exist within the juvenile criminal justice system, affecting minority groups. There is social bias from being targeted to even probation. I believe the youth are tomorrow's future, but targeting them and dehumanizing them is often incorrect. I believe we all need equal chances to better ourselves. The juvenile system should be a system that should be helping the youths reform, but it is doing more harm than good. Minority groups are often disadvantaged since they do not receive fair treatment. The juvenile criminal justice system can help reform the youths.

\section{REFERENCES}

[1] BOND, D. M., HOMAN, J., \& BEACH, B. (2020). DBT in Juvenile Justice Programs. Dialectical Behavior Therapy in Clinical Practice: Applications across Disorders and Settings, 159.

[2] de Sequeira, L. (2021). LAW ENFORCEMENT PERCEPTIONS OF YOUTH DIVERSION: A CASE STUDY OF THE DURHAM REGIONAL POLICE SERVICE (Doctoral dissertation).

[3] Florida Juvenile Justice Probation and Community Intervention | Florida Department of Juvenile Justice. Djj.state.fl.us. (2021). Retrieved 5 August 2021, from http://www.djj.state.fl.us/services/probation.

[4] Justice, N. (2021). Population projection for youth ages 0-17, 2020-2060. Ojjdp.gov. Retrieved 5 August 2021, https://www.ojjdp.gov/ojstatbb/population/qa01101. asp?qaDate $=2020$.

[5] Racial and Ethnic Disparities. Office of Juvenile Justice and Delinquency Prevention. (2021). Retrieved 5 August 2021, from https://ojjdp.ojp.gov/programs/racial-and-ethnic disparities.

[6] Sims, A. M., \& Dooley, D. G. (2020). Juvenile Justice and the Primary Care Pediatrician: Where Do I Fit? Pediatrics, 146(5).

[7] Quinn, C. R., Boyd, D. T., Kim, B. K. E., Menon, S. E., Logan-Greene, P., Asemota, E., ... \& Voisin, D. (2021). The influence of familial and peer social support on post-traumatic stress disorder among Black girls in juvenile correctional facilities. Criminal Justice and Behavior, 48(7), 867-883.

[8] Vasan, P. (2020). "JUVENILE REHABILITATION" JUVENILE JUSTICE SYSTEM. International Journal of Psychosocial Rehabilitation, 24(04), 1253-1263. https://doi.org/10.37200/ijpr/v24i4/pr201096 